\title{
Capacity Building For Entrepreneurship Education: The Challenge For The Developing Nations
}

John F. Eze, Federal Polytechnic, Nigeria

Anthony C. Nwali, Federal Polytechnic, Nigeria

\begin{abstract}
Entrepreneurship is one of the key drivers for development in any society. The level of awareness of individual members, of a society, of their capacity to contribute to the economic, social and political development of their society is a key factor in development. A process of creating this self-awareness and the development of individual capacity for creative and innovative thinking, decision making and action/policy implementation should be an integral constituent of what people learn in schools, colleges and universities. The ability of the educational system to provide such training for individuals depends on the availability of the requisite capacity in terms of personnel and other facilities for appropriate transfer of knowledge, skills and building of mindset. Thus, this paper focuses on ways for developing the capacity appropriate for providing entrepreneurship education at all levels of education particularly in Africa. This paper is of the view that a wholesome education integrating entrepreneurship as part of the curriculum will provide the catalytic platform for jumpstarting development in all spheres of life, particularly in the developing world. The paper tries to find out how capacity building for entrepreneurship education has been pursued with particular reference to Nigeria, and opine how best this can be achieved in the light of the perceived lack of entrepreneurial approach to doing things, including in the public service. Also, the low level of entrepreneurship education as exemplified in the number of entrepreneurship courses offered in our Higher Educational Institutions (HEIs) and the absence of entrepreneurship as courses of study that award certificates, diplomas and degrees in this part of the world are part of the factors necessitating this paper. Part of the focus of the paper also includes the possibility of inclusion of entrepreneurship in the educational curricula at all levels of education, establishing faculties of entrepreneurship studies in the colleges, polytechnics and the universities. It is obvious that these cannot be achieved without the necessary capacity in terms of personnel and other facilities that facilitate learning. Thus we are canvassing for a holistic approach to developing capacity for this, which should include training and retraining of personnel, including faculty members in the colleges, polytechnics and universities. There should also be a collaborative effort in terms of partnership with universities in the West where entrepreneurship education has taken root and are more developed. Such partnership should also include the private sector and the non-governmental organizations. The increasing economic and social challenges, especially in the developing countries, makes all this imperative.
\end{abstract}

Keywords: Entrepreneurship; Entrepreneurship Education; Capacity Building; Economic Development

\section{INTRODUCTION}

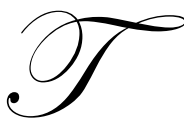

he global attention to entrepreneurship presently is borne out of the fact that it is a driving force for development. In particular, the developing countries' economies can be jumpstarted when massive attention is given to entrepreneurship. The case of China is supportive of this assertion. There is no doubt that since China started opening up its economy from the 1970s, a lot has changed within and outside the Chinese economy. There is no doubt that China is the next big thing. On the other hand, the American economy is 
what it is today because of the entrepreneurial mindset of the American people, which they carry to all sphere of existence. This has led to an economy that is not only leading the world politically, but is also dictating the tune of the global economy. President Obama, during the Chinese President's recent state visit to America, described the American economy as being three times larger than that of China. This is because private enterprise drives entrepreneurship; economies that favor private enterprise are clearly the best breeding spots for entrepreneurship development.

Therefore, the need for entrepreneurship arises out of the challenge of poverty and growing unemployment especially among graduates of tertiary institutions. Entrepreneurship education has become an important focal point of various governments because of its ability to unlock the economic potentials of the economy. Entrepreneurship education should be of interest to all in view of the inherent benefits of entrepreneurship - job creation, poverty alleviation, improvement in the living standard, creation of goods/services for the satisfaction of increasing population and bridging the gap between technology and satisfaction of human needs. More importantly, economies of most African countries particularly Nigeria have remained underdeveloped because of poor participation of the private sector arising out of lack of awareness that entrepreneurship education ought to have provided. The delay in allowing the economy to be private-sector-driven, of which we know that entrepreneurs drive the private sector, and the odyssey of government involvement in business operations have contributed to keeping the economy down for a long time. This has led to a continual rise in unemployment rate leading to many social vices - armed robbery, kidnapping, violence in different forms, advance fee fraud (popularly called " 419 " in Nigerian parlance), which in themselves impede development.

Promoting entrepreneurship development through a properly coordinated education would assist in changing this scenario. Most Asian countries, particularly China and India, are fast developing today because of the level of awareness on the importance of private sector involvement. This is attainable through entrepreneurship education. Building the requisite capacity to realize this is therefore an important prerequisite. These issues are the focus of this paper.

\section{CONCEPTUAL DEFINITIONS}

In economics, all human resources involved in paid employment for the production of goods and services are generally referred to as "labor". (Danko, 2006). However, entrepreneurial activity is another area of human impact that is generally considered and accepted to be superior in view of the following features:

- $\quad$ an entrepreneur, unlike paid employee takes initiatives in combining and allocating resources;

- $\quad$ an entrepreneurs makes policy decisions;

- an entrepreneur is an innovator who is always immersed in the art of creating new ideas/products/businesses;

- he is a risk taker/bearer.

At success, he reaps the rewards of his efforts, time and abilities, otherwise the business goes into extinction if he fails. The entrepreneur not only risks time, effort and business reputation but his invested funds and those of his close associates or stockholders (McConnel, 1981 in Nwaokolo, 1997).

Entrepreneurship has been seen in terms of the willingness and ability to seek out investment opportunities or ideas to establish and run an enterprise successfully - creating a new venture. (Inegbenegbor, 1989; Zimmerer and Scarborough, 2005; Olagungu, 2008; Eze, 2010). In this context, the desire and the courage to invest in untapped or not fully tapped opportunities is not just what distinguishes an entrepreneur from paid employee but also the ability to manage the business profitably/successfully. Value creation or addition and risk taking are also concepts that have been used to describe entrepreneurship. Hisrich (2002) defines entrepreneurship as "the process of creating something different with value by devoting the necessary time and effort; assuming the accompanying financial, psychological and social risk; and receiving the resulting rewards of monetary and personal satisfaction." Entrepreneurship is not just identifying opportunity and taking advantage of it, but it also requires that sufficient time and effort (mental, physical) must be put in order to create value. 
The University of Ohio has described entrepreneurship in the following way: “... the process of identifying, developing and bringing a vision to life. The vision may be an innovative idea, an opportunity, or simply a better way to do something. The end result of this process is the creation of a new venture, formed under conditions of risk and considerable uncertainty" (Kurya, 2006). This means that entrepreneurship is a deliberate effort to create value through identified business opportunity by bringing together all the necessary inputs (human and material) to actualize the dream. However, whichever form, dimension and scope one looks at entrepreneurship, the bottom-line of its importance to any economy is the transformation of ideas into economic opportunities.

Entrepreneur has been defined from authors' perspectives: "an individual who has the ability to identify opportunity where others see nothing and also being able to mobilize the necessary resources to translate such idea into viable business" (Eze, 2010); "a person, organization or government who establishes an organization for the purpose of making profit or other personal aims Olagunju, 2008).

Entrepreneurship education seeks to change people's attitudes and beliefs and to equip them with the skills necessary to plan, launch, and successfully manage their own business enterprises. (Akhuemonkhan, 2005). He further rightly observes that the underlying assumption of entrepreneurship education is that potential entrepreneurs can be identified and trained. "Entrepreneurship education therefore is a process of changing people's mindset towards applying creative thinking and innovative approach to solving identifiable problems, or improving systems in which they find themselves" (Eze, 2011). The processes and procedures, or opportunities created for people to begin to have the self awareness and to begin to think and act creatively is what entrepreneurship education is all about.

\section{OVERVIEW OF ENTREPRENEURSHIP DEVELOPMENT, EDUCATION AND CAPACITY BUILDING IN NIGERIA}

\section{Entrepreneurship development effort}

Efforts at entrepreneurship development in Nigeria abound. For example in 1970s during the oil boom era, the Federal Government established certain institutions including the Nigerian Industrial Development Bank (NIDB), the Nigerian Bank for Commerce and Industry (NBCI) and the Nigerian Agricultural Development Bank. This was done with the expectation that they would provide credit facilities and support for existing and budding entrepreneurs. More recently, government has established other agencies that focus on supporting the development of entrepreneurship activities. Some of these include the National Directorate of employment, established around 1986 with the purpose of training unemployed youths and retired persons for vocational skills acquisition, entrepreneurship or business development, labor based works, rural employment promotion and job placement guidance and counseling (NDE, 2010). The Obasanjo administration, 1999 - 2007, also established the Small and Medium Enterprises Development Agency of Nigeria (SMEDAN) with the purpose of promoting the development of small and medium enterprises sector, which is the hub of entrepreneurship activities. There are also several industrial and trade associations that through their activities seek to promote the development of entrepreneurship activities. Some of these include the National Association of Small-scale Industrialists, chambers of commerce, National Employers Consultative Assembly, and so on. Educational institutions that offer entrepreneurship courses are supposed to create avenue for interaction between their students and staff and some of these organizations.

\section{Entrepreneurship education}

The Nigerian government started introducing entrepreneurship as part of university and other HEIs' curricula around 1989/1990 when entrepreneurship courses were introduced for the 200 and 400 levels. It was only the business schools/faculties that benefited from this introduction, particularly business management, marketing and purchasing and supply. These courses were only offered by students in only a single semester of their course of study.

Subsequently, in 2003 the National Board for Technical Education (the body overseeing polytechnic education in Nigeria) introduced new curriculum (a collaboration with UNESCO gave rise to this) for the engineering and sciences, which incorporated entrepreneurship courses. These courses were offered in first year and second year and for some in the third year (i.e. first level of the Higher National Diploma program). 
Furthermore in 2007 the Board introduced a new curriculum on entrepreneurship education, (EEd). Under this new arrangement all students, irrespective of the course study, must offer entrepreneurship courses both at the National Diploma and Higher National Diploma levels. This time a more encompassing approach has been developed, which include theoretical work and practical activities. Students are expected to participate in one skill activity or the other as integral part of the course at any levels it is offered. Students are graded in these courses in both the theoretical work and the practical. In some cases the weight is fifty/fifty (50/50) for the theory and practical and the student must participate in both to be able to have a pass grade in the course. Entrepreneurship education centers in the various institutions are coordinating all this. The operational guideline for managing such a centre as provided in the curriculum book is illustrated in the diagram below.

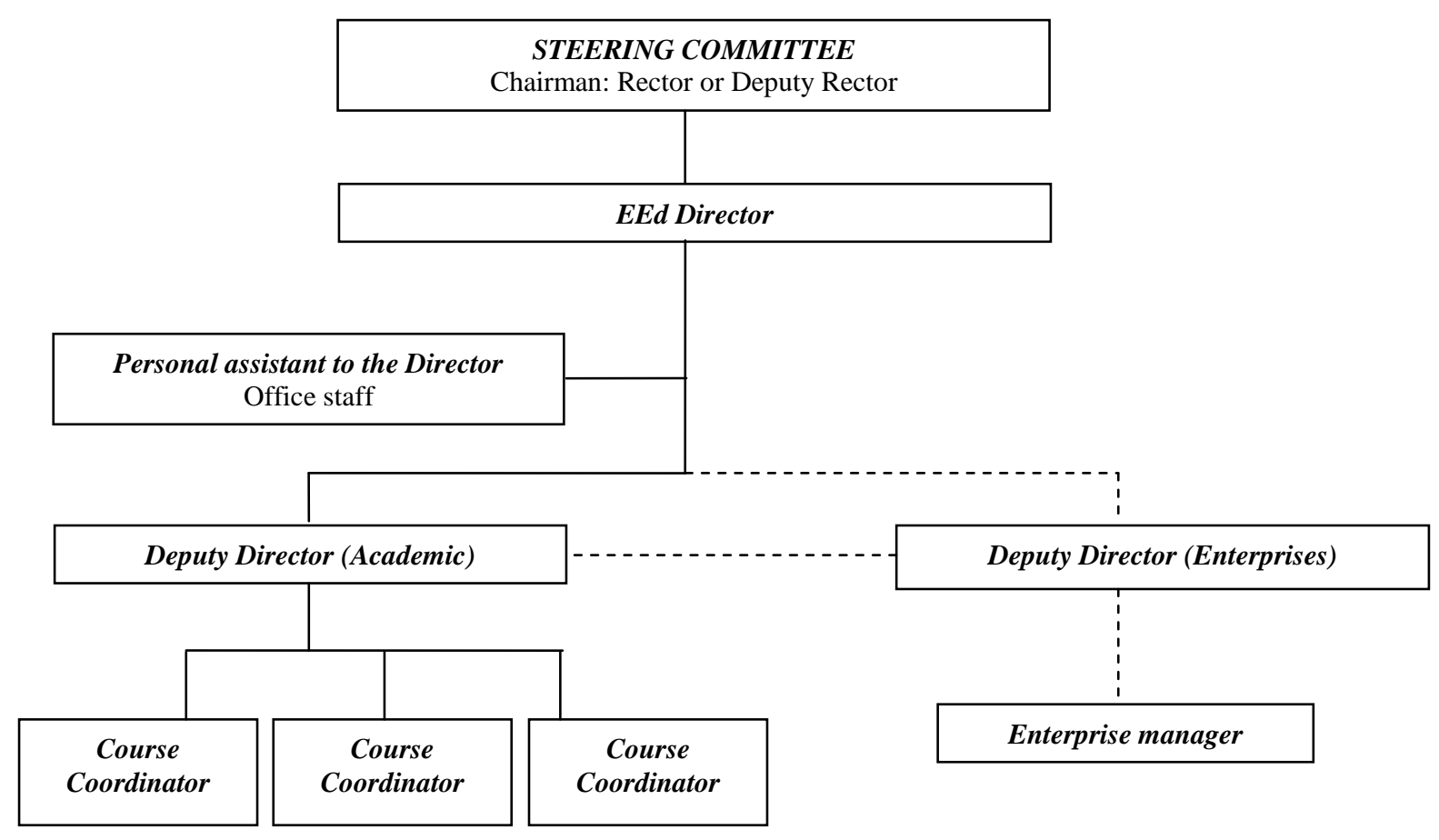

Figure 1: EEd operational guideline for polytechnics in Nigeria.

Source: NBTE Entrepreneurship education curriculum and course specification, 2007, p. 10.

This new package came as a result of high level brainstorming that took place in 2006 involving Vice chancellors of universities, Rectors of polytechnics and Provosts of colleges of education nationwide. This session gave rise to a new policy of government on entrepreneurship education. As at this present time only the polytechnics have pioneered the practical training dimension of this new policy. The exceptions are few universities including Covenant University that is actually pioneering entrepreneurship education in a very practical and realistic way. Others are University of Benin and Obafemi Awolowo University, Ile-Ife.

However, by the end of January 2011, the Federal government through the Minister of education of the Federal Republic of Nigeria directed all universities to set up entrepreneurship education centers in their campuses. By this time those of the polytechnics are already taking root and getting well established. Such centre is saddled with the function of coordinating entrepreneurship education in each institution. In addition, the universities are to start offering courses of study or programs leading to the award of degrees in entrepreneurship. This is to take effect from 2011/2012 academic session. 
This type of education is meant to inculcate in the students (NBTE, 2007):

- $\quad$ creative ingenuity, self-reliance and capacity to respond to change, and ability to generate, recognize and seize opportunities;

- $\quad$ a good perception of the demand and challenges of the work place;

- $\quad$ ability to identify opportunities within the work place and to apply initiative;

- $\quad$ the ability to take a greater degree of responsibility for the quality of their work.

It also helps to build a learning culture that empowers young people to take responsibility for their own future (entrepreneurial culture); and a good perception of the relationship between their school, immediate community, and business and industry.

\section{Capacity building}

In terms of capacity building not much is seen to have been done with reference to the entire spectrum of the educational and training program nationally. However, the National Board for Technical Education, NBTE, has done substantial work in terms of capacity building. There has been a number of training sessions/programs proceeding from the high level brainstorming program which was organized in 2006. Such programs include Executive capacity building training session that took place in Songhai Centre, Porto Novo, Benin Republic in 2008, which involved Rectors of polytechnics and Provosts of colleges of education, and the personnel in charge of entrepreneurship education in the various institutions. Another one followed in 2010, involving the Directors of entrepreneurship education centers in the various institutions, which lasted for three weeks per session/slot.

In addition to the above, the NBTE and the Education Trust Fund have also jointly organized nation-wide train-the-trainer programs for Lecturers of these institutions. To complement these and as offshoot of the train-thetrainer sessions, institutions at their various levels have also organized training sessions on entrepreneurship education for their lecturers who are to train the students. Consequent upon the policy thrust of government, entrepreneurship education centre in each of the polytechnics has been on since 2007/2008 academic session driving the training of students in entrepreneurship. These efforts however, are not without challenges.

The first could be seen in the cynicism that naturally almost always follows a new thing or innovation. For example while these efforts are being made in the Polytechnic sector, the universities remained aloof and there has also been some level of criticism from the university personnel of what the polytechnics are doing. However, it is worthy of note that the government has directed the universities to follow suit as a matter of policy initiative as enunciated in the new policy on entrepreneurship education. Secondly, overcoming the initial critical issues at start up is far from being achieved. Prominent among these are the human capital and physical facilities that would support the achievement of the targeted objectives. The third and the most critical is the issue of funding. Providing the needed fund to train and retrain persons involved in entrepreneurship education requires a lot of money if it has to be comprehensive enough to build a solid foundation. Facilities, equipment and tools critical to the hands-on activities involved in the project also require substantial amount of funding. This is more worrisome considering the budgetary provisions for education sector in most of the developing nations like Nigeria, which usually fall far below the united nation's recommendation ( 26 percent or thereabout).

\section{ENTREPRENEURSHIP EDUCATION, CAPACITY BUILDING AND ECONOMIC DEVELOPMENT}

Entrepreneurship education is a deliberate attempt tailored towards the building of knowledge and skills about entrepreneurship. This should form part of the recognized education programs at primary, post basic and tertiary levels. Educational institutions at all levels need to adopt approaches aimed at encouraging creativity, innovation, critical thinking, opportunity recognition, and social/self awareness. Entrepreneurship thrives in an economic system where diverse stakeholders play key roles. Central to providing entrepreneurship education are academic institutions. Through entrepreneurship education young people, including entrepreneurship facilitators that have been trained, even those with disabilities learn organizational skills, time management, leadership development and interpersonal skills needed to organize a venture, the conglomeration of which are needed to give effect to economic growth and development. 
Organizational skill has to do with the ability to combine the work which individuals or groups have to perform with the facilities necessary for its execution, so that the duties so performed provide the best channel for the efficient, systematic, positive and coordinated application of available resources and effort. As an enterprise grows and expands, application of organizational skills acquired through entrepreneurship education become inevitable. Time management has emerged as a significant practice to increase productivity and efficiency. Most productivity and process related practices also result in time saving. Organizational mechanisms such as delegation are preferred as they enable entrepreneurs to focus on critical activities through 'management by exception' or the ' $80: 20$ ' principle. This is a situation where 20 percent of the activities result in 80 percent of achievement is emphasized. This also is made possible where people are trained and retrained to provide entrepreneurship education. Leadership development involves the process of developing entrepreneurs on the art of influencing and inspiring others to perform their duties willingly, competently and enthusiastically for the attainment of the enterprise objectives. This is vital to the success of any enterprise as most business start-up failures at that level can be attributed to ineffective leadership. Interpersonal skill has to do with the ability to relate with other people. With this skill, the entrepreneur is expected to play or perform social or legal obligations (figurehead role); role of a liaison officer where he maintains a network of outside contacts in order to assess the external environment of competition and social change; and the inevitable leadership role.

Garba (2010) rightly points out that poverty reduction strategies should be multi-faceted, adding that any country's educational system must be considered as an essential ingredient to foster economic growth and development. Furthermore, there is also the indication that research has shown that in both developing and developed there is evidence to support a positive and significant relationship between education and entrepreneurial performance whether performance is measured in terms of growth, profit or earning power of the entrepreneur (Dickson, Solomon \& Weaver, 2008). Ijaiya (2007) justifies entrepreneurship education in school curriculum as follows: "With the proliferation of schools, colleges and universities, Nigeria has produced army of unemployable and unemployed youths. The result of this is the agitation for entrepreneurship education as one of the ways to solving youth unemployment." The aim of course is to adequately prepare the graduate for the challenges of life after school in the light of dwindling opportunities for paid employment. Self employment therefore is a viable option. And just like Aladekomo (2004) rightly observed tertiary institutions and particularly universities have a role to play in preparing the youth for the world of self-employment. Entrepreneurship education appropriately modeled should be perceived to address this because unemployment is a serious indicator of economic unhealthiness. Unemployment is common denominator among the developing nations.

\section{COLLABORATION FOR CAPACITY BUILDING AND EDUCATION}

Creating "unique enterprise" begins with a clear sense of what students should know and be able to do. Entrepreneurship as a career option has emerged due to the cut-throat completion and lack of opportunities in the formal sector. Individuals with dreams to do something on their own are even leaving their secure jobs to pursue a business venture.

India and China are some of the countries where awareness on entrepreneurship education has grown tremendously. In India, specifically, their institutions of higher learning offer courses in entrepreneurship leading to the award of diplomas, degrees, post-graduate diplomas and certificates. This is aimed at preparing prospective entrepreneurs on ways of confronting the challenges of entrepreneurship as a career. For people to become entrepreneurs there is the need for education and exposure to the principles and practices of entrepreneurship. It is therefore imperative for developing countries like Nigeria to take after countries like China and India in developing capacity for entrepreneurship education. This step should not be limited to tertiary institutions but rather form primary level considering the enormous resources Nigeria is endowed with.

The United States of America, no doubt, is the most advanced in terms of practice and education and training in entrepreneurship. Universities offer degrees and postgraduate degrees in entrepreneurship. At the moment there is no institution in Nigeria that offers certificate, diploma or degree in entrepreneurship. this is why the directive to the universities in Nigeria to start offering such programs from 2011/2012 academic session is a tall order. This is in view of the human capacity challenges posed by that directive. Though the Minister was optimistic in declaring that the lecturers would not be a stumbling block, it is necessary to point out that collaboration with 
countries like the USA, India, Malaysia, United Kingdom, etc. for some sort of exchange program and training of lecturers would be a step in the right direction. We agree with Liyan (2010) that if university students with high entrepreneurial potentials get proper training, they will have the best prospects for becoming real entrepreneurs.

Already, Lecturers are being sponsored abroad in places like Malaysia, England and India by the Education Trust Fund, an agency of the Federal Government of Nigeria. It would be rewarding to expand such sponsorship to $\mathrm{PhD}$ programs and priority given to entrepreneurship. Entrepreneurship and the small and medium enterprises sector are key to economic growth and development. For the developing nations no sacrifice would be too great to promote them.

\section{CONCLUSION}

The key role entrepreneurship plays in economic growth and development makes it an important factor demanding attention of all stakeholders - government, educationists, politicians, social change agents (social entrepreneurs), and so on. Changing people's mindset or building the entrepreneurial mindset is very important. Applying entrepreneurial principles implies goal-driven approach to work. This is important both in the private sector and the public sector as well. Building of such mindset is possible through education and training. The question is: do developing nations have the required capacity adequate entrepreneurship education and training. The educational systems in most of these nations have not been adequately tailored to foster entrepreneurship mindset.

This is why, considering the place of entrepreneurship in economic vibrancy, we are of the opinion that educational curriculum should be made to include functional entrepreneurship education and for this to be possible there should be a collaboration with the nations that are already advanced. When the first sets of universities were established in Nigeria for example, Europe and America (particularly Britain and United States) provided the needed support and leadership. In the same vein establishing faculties or departments to award degrees in entrepreneurship should be done with support and assistance from places such as United States, United Kingdom, India, etc. who are leading in entrepreneurship education.

We have identified the effort so far made in building capacity for entrepreneurship education, particularly by the polytechnic sector in Nigeria, but a lot still need to be done, consequently, collaboration in education and training is very vital if the goal of economic development and the drive to conquer poverty are to be realized. The Nigerian government directive for all universities to introduce entrepreneurship education centers and departments to award degrees in entrepreneurship represents a significant paradigm shift and needs to be supported by appropriate man power. This will enable the institutions to achieve the desired objective, which will automatically translate to economic well being. This is why such partnership is advocated.

As a corollary to this, entrepreneurship should be made compulsory part of education curriculum at all levels of education. The entrepreneurial approach - goal achievement drive - if imbibed from the very beginning will definitely affect positively our work culture and the economy at large. Practicing entrepreneurs should be part of those who design the curriculum. We are convinced with Allahwerdi \& Westerholm (2008) that the traditional teacher's role will change into the role of active communication and cooperation with the world of work, if this is done. The practical dimension of the entrepreneurship education will strengthen the students' abilities, skills and attitudes and we also believe that "creativity is more meaningful than competences". Equally, it is important to note that "A society with high levels of knowledge and skills will not produce the breakthroughs in products or processes needed for economic advance without a culture of entrepreneurship that extends across society." (Faustino, 2009).

There should also be a monitoring program to ensure that the desired results envisaged in designing the curriculum are achieved. This monitoring should involve both academics and practitioners to create a bridge between the study program (school activities) and the world of work.

\section{AUTHOR INFORMATION}

John F. Eze, The Federal Polytechnic, Nigeria. E-mail: jfeze@ yahoo.com. Corresponding author. 
Anthony C. Nwali, The Federal Polytechnic, Nigeria.

\section{REFERENCES}

1. Akhuemonkhan, I. A. (2005). Modalities of teaching entrepreneurship in technical institution. A paper presented at the National workshop on capacity building for lecturers of Polytechnics and monotechnics in Nigeria, at the Federal Polytechnic, Uwana, Afikpo, Nigeria; (October 3 - 7, 2005.

2. Aladekomo, F. O. (2004). Nigeria educational policy and entrepreneurship. J. Soc. Sciences., 9(2): 75-78

3. Allahwerdi, H. \& Westerholm, H. (2008). Family business entrepreneurs' influence on entrepreneurship education and training - a discussion paper. Paper prepared for FBE 2008, Best Practices on Family Businesses and Entrepreneurship Higher Education. August 21-22, 2008, University of Jyvaskyla, Finland.

4. Danko, A. I. (2006). Entrepreneurship in vocational and technical education in entrepreneurship education for vocational and technical students. $2^{\text {nd }}$ edition. Kano, Nigeria: Benchmark Pub. Ltd.

5. Dickson, P.H., Solomon, G.T. \& Weaver, K.M. (2008). Entrepreneurial selection and success: Does education matter? Journal of small business and enterprise development. 15(2), pp 239-258.

6. Eze, J. F. (2011). Entrepreneurship education for self-reliance and implications for the Millennium Development Goals. Being a paper presented at the sixth international conference on development studies at Benue State University, Makurdi, Nigeria (February 2 -3, 2011)

7. Eze, J, F. (2010). Introduction to entrepreneurship. Abuja: Supreme Command International Ltd.

8. Faustino, J. (2009). The spirit of entrepreneurship in Asia. Wikipedia, the free encyclopaedia. Retrieved from: www.idrc.ca/.../11231726411Faustino The Spirit_of_Entrepreneurship_in_Asia_Final.doc-

9. Garba, A. S. (2010). Refocusing education system towards entrepreneurship development in Nigeria: a tool for poverty eradication. European journal of social sciences, 15(1): 140-150. Retrieved January 20, 2011, from http://www.eurojournals.com/ejss_15_1_13.pdf

10. Hisrich, R. D. (1996). Entrepreneurship and intrapreneurship: methods of creating new companies that have an impact on the economic renaissance of an area, in entrepreneurship, intrapreneurship and venture capital, Robert Hisrich (ed.), M.A. Lexington Books.

11. Ijaiya, B. S. (2007). Addressing youth unemployment through entrepreneurship education. Ilorin journal of education, vol27, August, 2007.

12. Inegbenebor, A. G. (1989). Entrepreneurship, in foundations of business administration. Ejiofor, P. (ed.). Onitsha, Nigeria: Africa-FEB publishers Ltd.

13. Kurya, U. L. (2006). Concept of entrepreneurship and types of entrepreneurs, in entrepreneurship education for vocational and technical students, $2^{\text {nd }}$ ed. Kano, Nigeria: Benchmark publishers Ltd.

14. Liyan, Z. (2010). Entrepreneurship education within India's higher education system. Retrieved January 20, 2011, from http://www.asianscholarship.org/asf/ejourn/articles/zhang_l.pdf

15. NDE (2010). National Directorate of Employment Charter. Retrieved July 9, 2010, from http://www.servenigeria.com/charter/labour_nde.doc

16. Nwaokolo, P. O. (1997). Entrepreneurship in technology education in Africa: a panacea for youth unemployment. Journal of technical teacher education, 2(1).

17. Olagunju, Y. A. (2008). Entrepreneurship and small-scale business enterprises development in Nigeria. Ibadan: UPL. 